\title{
An aberrant bald eagle (Haliaeetus leucocephalus) with multiple anatomical abnormalities
}

\section{Jeremy J. Klingler ${ }^{1, \star}$ and Christine N. Glasmann ${ }^{2}$}

${ }^{1}$ School of Biological Sciences, University of Utah, 257 South 1400 East, Salt Lake City, Utah, 84112, USA; jeremy.j.klingler@gmail.com ${ }^{2}$ Department of Integrative Biology, University of California Berkeley, 3040 Valley Life Sciences Building, Berkeley, California, 94720, USA; glasmannchrissy@gmail.com

\begin{abstract}
Genetic abnormalities, especially polydactyly, are quite common among birds. Although there are numerous accounts of anatomically abnormal birds with polydactyly, few written anatomical descriptions have elucidated whether or not these physical aberrations extend to the musculoskeletal structure of the feet. Here, we present the findings of a dissection of a 14-week old female bald eagle that exhibited polydactyly and numerous other aberrations and discuss the functional impact these aberrations would cause. The specimen displayed a myriad of feather anomalies including missing feathers (i.e., had never grown in), ingrown feathers, stress bars, and most strikingly, bifurcated feathers wherein two feathers were seen to grow out of one rachis. Further, an extra, anomalous tendon was observed stemming from the tendinous origin of the $m$. extensor carpi radialis. The carpometacarpi were unable to reach full extension, stopping at less than $140^{\circ}$, and had phalanges bent downward at $45^{\circ}$. This mobility is limited in comparison to that of a normal bird. Most notably, the specimen exhibited polydactyly with one extra hallux on each foot. Several tendons of the left foot were seen to have aberrant connections as well.
\end{abstract}

\section{INTRODUCTION}

Genetic diversity and variation is important in a species' evolutionary fitness and is often viewed in a positive light. However, some genetic discrepancies can severely hinder an animal's ability to execute tasks vital to its survival, such as prey capture or locomotion. Polydactyly is a condition in which a vertebrate exhibits additional phalanges. This physical abnormality, and more generally any physical abnormality, may be the consequence of environmental conditions, genetics, or unknown reasons (Pourlis 2011). Among birds, polydactyly has been well-documented in domestic as well as wild species (e.g., Reichnenau 1880; Coale 1887; Lönnberg 1907; Bebe 1910; Ester 1937; Cole 1942; Landaver 1946; Taylor and Gunns 1947; Kummerloeve 1952; Cooper 1984; Fox 1984; Heidenreich 1997; Trinkaus et al. 1999; Samour 2000; Vedde 2000). Polydactyly can come with a multitude of other abnormalities (Hollander and Levi 1942). In pigeons, for instance, alongside polydactyly, Hollander and Levi (1942) observed other characteristics including short nestling down, defective plumage, an undershot beak, and shortened legs. Extreme environmental stressors, such as wildfires, can induce multiple abnormalities in developing embryos, such as stress bars and polydactyly, as seen in a blue-fronted Amazon parrot (Amazona aestiva) nestling (Herrara and Berkunsky 2017). Although there are many accounts of polydactyly, there is surprisingly little information on the musculoskeletal anatomy that makes up these physical abnormalities. For instance, with the duplication or expression of additional digits, do the tendons also duplicate or are there aberrant connections where the muscles/tendons insert? The omission of these studies represents a serious deficit in our understanding of aberrational anatomy. Here, we describe a juvenile bald eagle (Haliaeetus leucocephalus) with polydactyly and multiple other abnormalities. We compare the anatomy of the abnormal bird with that of a developmentally normal bald eagle of similar age.

\section{METHODS}

Two juvenile bald eagle specimens, one abnormal and one normal, were dissected (fresh, frozen, and thawed). The abnormal specimen (specimen number 2017-01134; accession number N1715533 Pennsylvania Animal Diagnostic Laboratory System) was a 14-week old female nestling 
that had never fledged. This specimen's nest was from Columbus, New Jersey near an area that had recently been cleaned up of arsenic contamination; however, there was no evidence of toxins in the body. Thus, the deformities may have been genetic or developmental in origin. This bird was captured and brought to the Mercer County Wildlife Center (New Jersey) after it was found when the nest had fallen out of the tree. Evaluation of the bird concluded that although it could perch and use all toes on each foot, it was not a viable candidate for release given the discovery of numerous anatomical anomalies, and the inability to extend its wings. The bird was anesthetized with isoflurane, and then humanely euthanized with pentobarbital injected intravenously. The normal specimen (band number 171208; accession number N1714552 Pennsylvania Animal Diagnostic Laboratory System) was a male with the plumage and development of a recent fledge (11-16 weeks). This animal was found weak and emaciated, was diagnosed with disseminated aspergillosis, and was humanely euthanized. The normal specimen was found in Annapolis, Maryland, and is therefore not related to the deformed specimen.

Specimens were worked on under the following permits: MCWC Federal Wildlife rehabilitation permit \#MB777794; MCWC NJ Wildlife rehabilitation permit \#2017-2192; MCWC NJ Endangered species permit \#ES2017038; and MCWC NJ Wildlife salvage permit \#SB2016037. Upon completion of the study, both specimens were sent to the National Eagle Repository (Commerce City, CO, USA).

Both specimens were dissected to compare the anatomical differences between certain regions of interest, particularly the wings and feet. Anatomical terminology follows the Handbook of Avian Anatomy: Nomina Anatomica Avium (Baumel et al. 1993).

\section{RESULTS}

The following section details all the significant issues the abnormal bald eagle specimen exhibits that would impair normal function contrasted with the normal condition.

\section{Feathers}

Numerous abnormalities are associated with the feathers. First, many feathers (primaries, secondaries, and retrices) exhibited stress bars indicative of poor nutrition, stress, and/or general illness (Fig. 1A). Many of these feathers had deeply cutting stress bars which cut off the ends of the barbs. Second, some primary remiges retained the sheath along the rachis (Fig. 1B). Third, some primaries of the right forelimb exhibited severe curvature laterally rather than exhibiting straight-to-slight medial curvature (Fig. 1C). Fourth, some primary feathers on each wing were ingrown in the follicle of the calamus (Fig. 1D). Fifth, numerous primaries, secondar- ies, and body contour feathers exhibited peculiar bifurcations wherein the feather's rachis split in two somewhere along the rachis forming two distinct feathers emerging from one central stem. In at least three feathers, it was observed that the rachis split in a left-right manner (Fig. 2A). More commonly, the feathers split in such way as to produce a front-back/ overlapping bifurcation (Fig. 2B, C). Sixth, some primary and secondary feathers were missing (i.e., never formed; Fig. 2D). Issues such as deep cutting stress bars curved primary remiges, and the absence of primaries and secondaries would severely impact the animal's ability to generate lift and properly fly.

\section{Forearm}

M. extensor carpi radialis: This muscle has a tendinous origin on the distal end of the humerus on the lateral epicondyle, and the muscle inserts on the extensor process of the carpometacarpus. This muscle acts to extend the carpal joint at the wrist. The muscle courses along the dorsal surface of the radius and its belly is about as long as half the length of the forearm before it becomes a stout tendon distally towards the carpometacarpus. Overall, this forearm muscle is quite normal in the aberrant specimen, except in one respect. In the right muscle of the abnormal bird exists a bizarre, anomalous, extra tendon stemming from

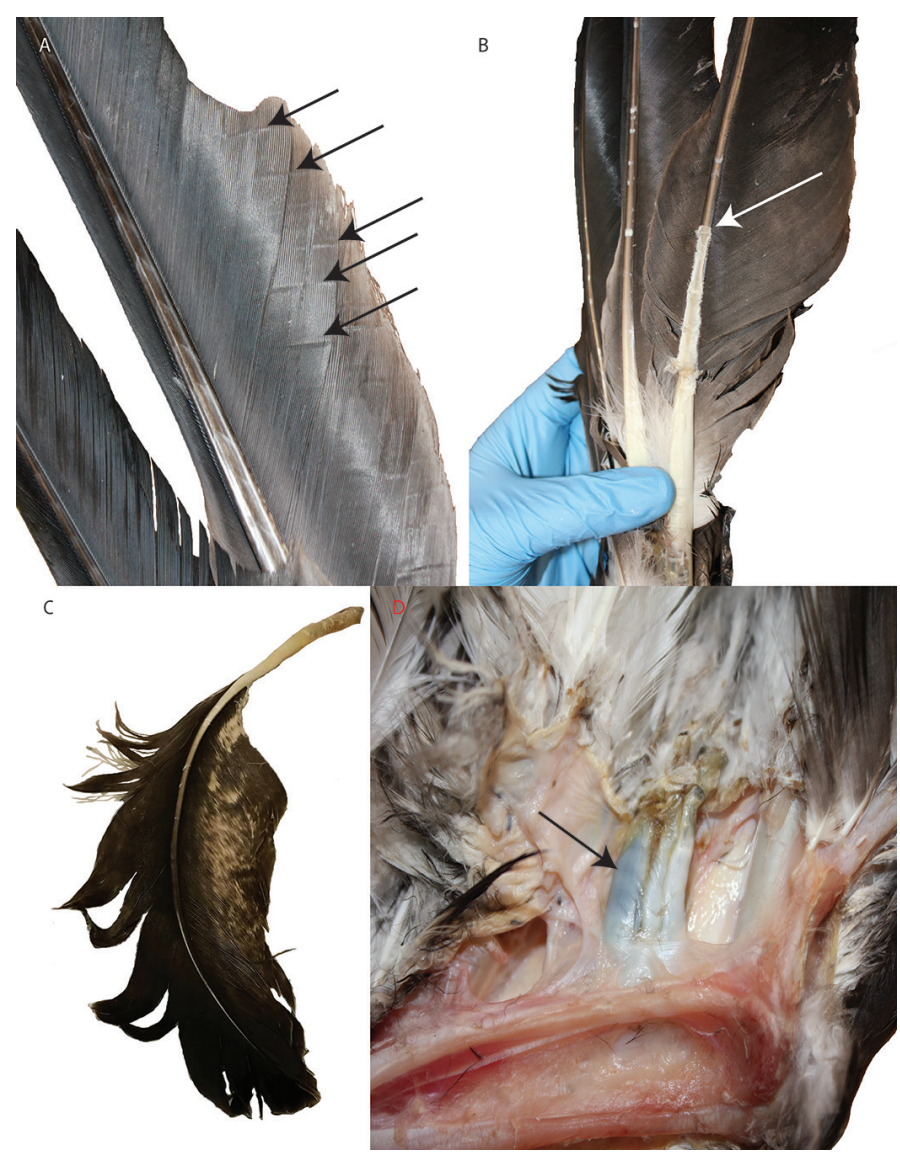

Figure 1. Feather anomalies. A, stress bars; B, extended sheath on rachis; $C$, curvature of primary; $D$, ingrown feather. Arrows indicate these features. 
Figure 2. Feather anomalies. A, bifurcated feather exhibiting a left-right split; B, bifurcated feather displaying a front-back split; $C$, another bifurcated feather with a frontback split; D, missing feathers can be seen on the wing (image courtesy of Erica Miller).

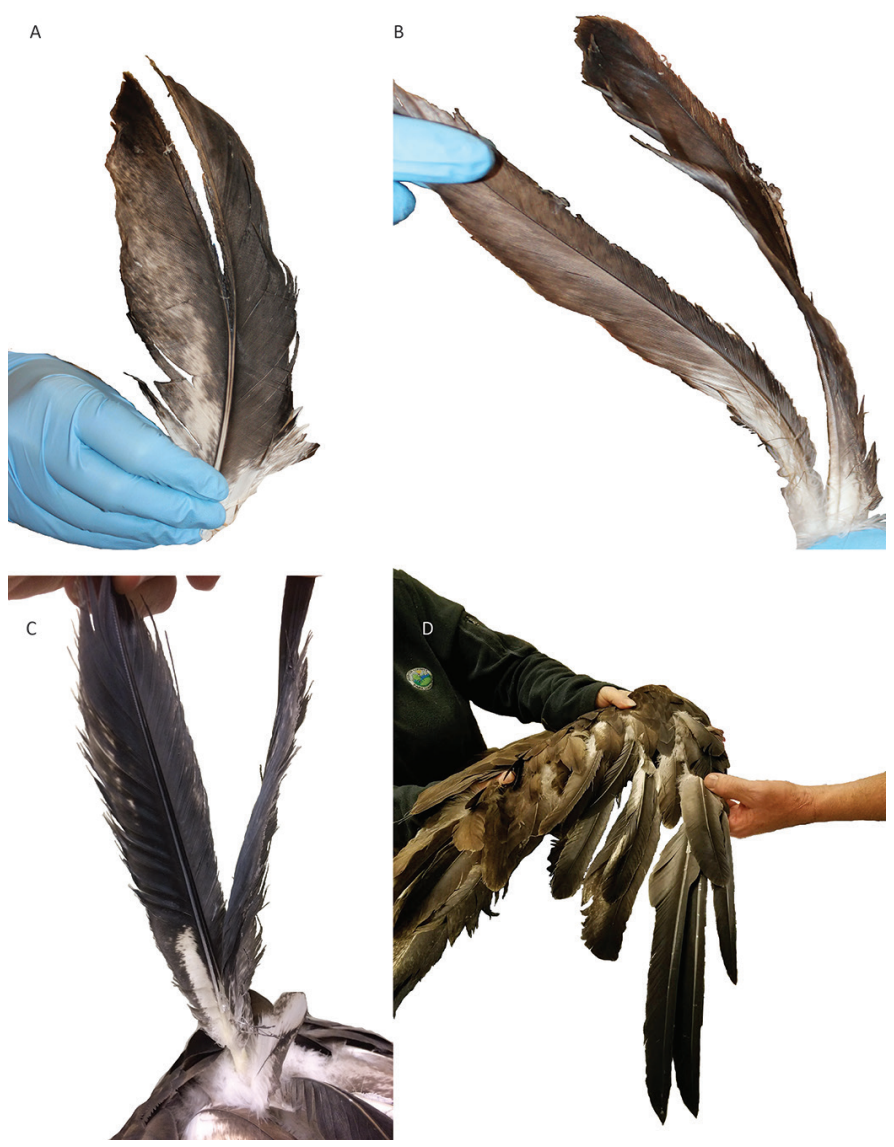

the tendinous origin of the $m$. extensor carpi radialis that passes distally $4 \mathrm{~cm}$ towards the hand, before inserting into the skin (Fig. 3). Functionally, we suggest that as the m. extensor carpi radialis contracts, this extra tendon would put tension on a very local area of skin near the elbow, likely minimally moving some feathers of the area.

M. pectoralis propatagialis: The $m$. pectoralis propatagialis takes its origin from the epicleidum of the furcula and inserts on the wrist joint. The muscle acts to create tension on the propatagium. No differences were observed for this muscle or its tendon between normal and abnormal specimens. The aforementioned extra tendon does not have any relation to the $m$. pectoralis propatagialis which often has additional tendons coursing to the junction of the humerus and radius/ulna. In the bald eagle, $m$. pectoralis propatagialis has a simple tendon that does not bifurcate unlike the condition in some birds (e.g., the night heron, Nycticorax nycticorax, Baumel et al. 1993; or the prairie falcon, Falco mexicanus, and the whooping crane, Grus americana, George and Berger 1966) and continues, without dividing, to insert on the wrist joint.
Figure 3. A, dorsal view of the extra tendon of the $m$. extensor carpi radialis. Arrow points to the extra tendon; B, line drawing of the dorsal forearm musculature of the bald eagle.
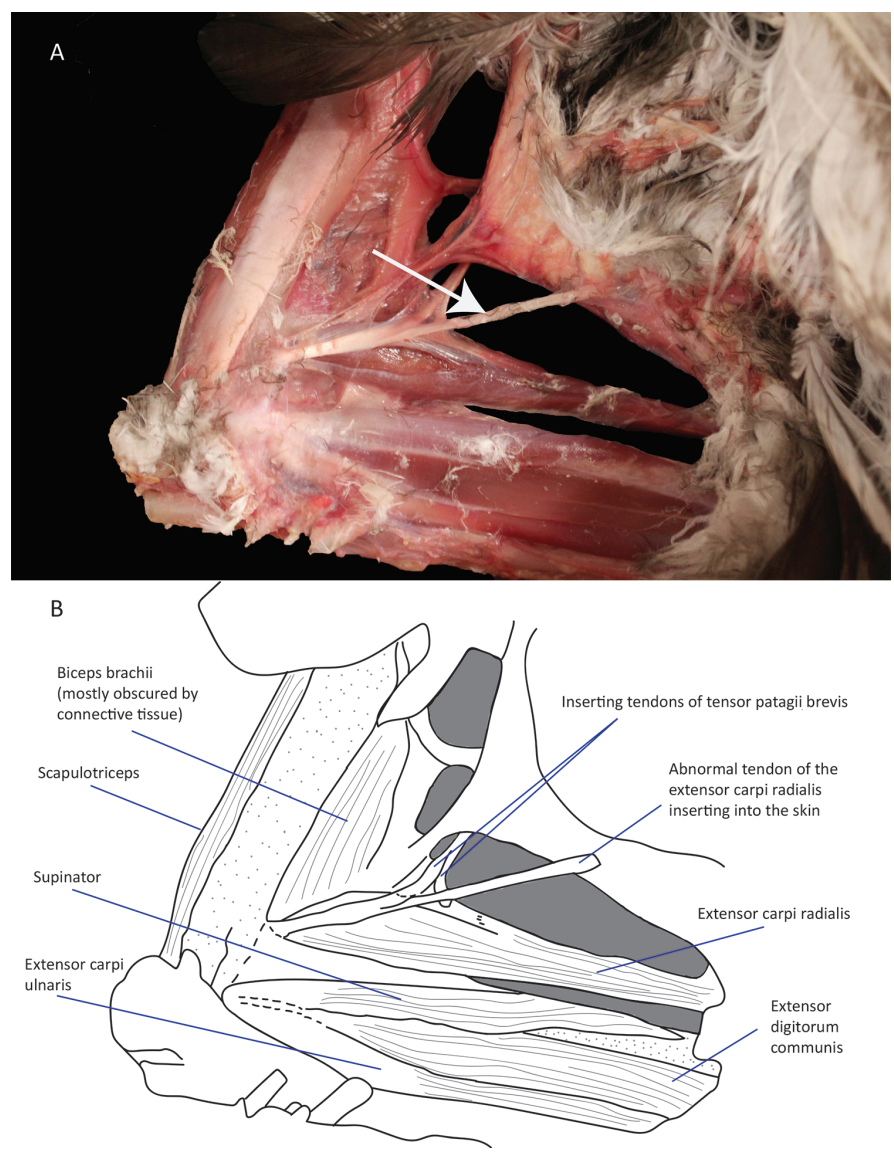

M. tensor patagii brevis: This muscle originates from the dorsal surface of the apex of the clavicle. The muscle inserts via a tendon that is anchored to the anterodorsal surface of the belly and/or tendon of origin of the $m$. extensor carpi radialis. There were no irregularities observed with this muscle or its tendons in either specimen. The anomalous tendon is not associated with the tendons of the $m$. tensor patagii brevis which has two tendinous insertions on the tendinous origin of the $m$. extensor carpi radialis. In the bald eagle, the $m$. tensor patagii brevis inserts via a main tendon onto the dorsal surface of the tendinous origin of the $m$. extensor carpi radialis. The main tendon of the $m$. tensor patagii brevis, however, splits less than $20-40 \mathrm{~mm}$ above its insertion point to insert with two tendons separated by about $10 \mathrm{~mm}$.

The anomalous tendon reported here clearly has no relation to the tendons of the $m$. pectoralis propatagialis or $m$. tensor patagii brevis and rather obviously branches, parallelly, off of the origin of the $m$. extensor carpi radialis as opposed to the other tendons. 


\section{Manus}

In the aberrant specimen, the joint of the right hand (carpometacarpus) cannot fully extend, but is limited to about $130^{\circ}$ extension. Additionally, there is a large amount of excess connective tissue covering the right carpometacarpus (Fig. 4A) ventrally, compared to the left in the aberrant eagle. The left carpal joint could not be extended more than about $140^{\circ}$ (Fig. 4B). In the normal bird, the carpal joint extended about $165-170^{\circ}$. In living bald eagles, it was observed that the carpal joint can extend $180^{\circ}$ and may extend to $210^{\circ}$ to hyperextend the wings' primaries (pers. comm. Erica Miller, 2017). Both phalangeal regions do not extend past a $45^{\circ}$ angle in the aberrant specimen (Fig. $4 \mathrm{C})$, whereas with the normal condition they extend up to $180^{\circ}$. Furthermore, the phalangeal region of both hands is severely rotated in the abnormal bird (Fig. 4D).

Problems with wing extension led us to investigate potential differences in the associated muscles. However, no differences in wing extensor muscles of either hand were found in either bird. The issue of limited wing extension is likely skeletal. In the abnormal bird, the carpal bone, the radiale, appeared to restrict full extension of the wings by making premature contact with the distal end of the radius and in articulating with the radius improperly would prevent full extension. Additionally, as the third finger has many primary feathers attach to it, the abnormal angle of attachment and severe rotation they displayed would splay those primary remiges in odd angles proving detrimental to the bird's ability to generate lift. Taken together, these abnormalities would have made it impossible for the bird to fly.

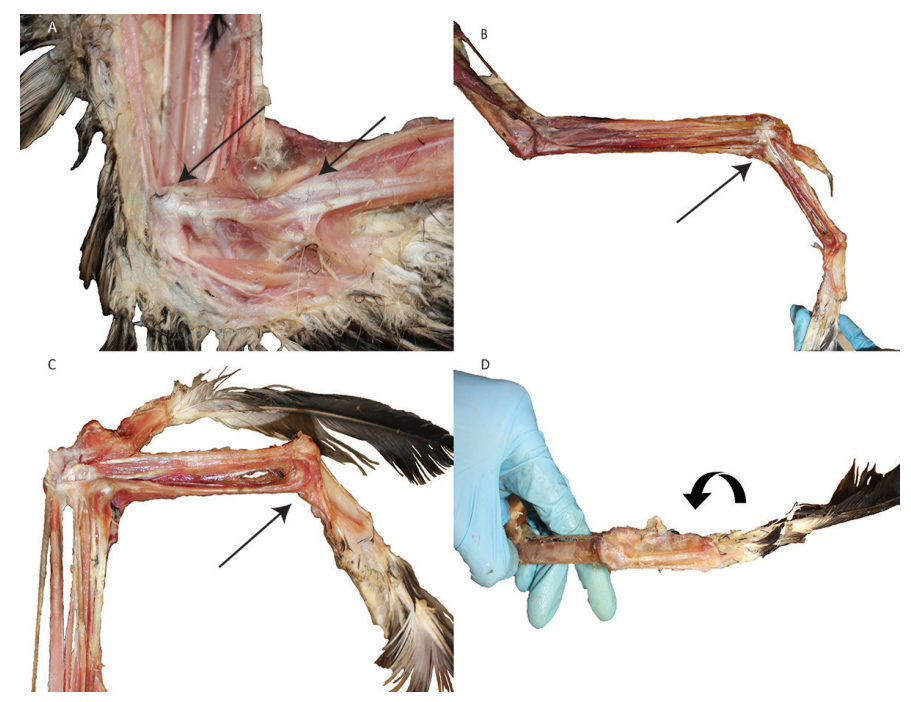

Figure 4. Hand anomalies. A, excess connective tissue of the right hand of the aberrant eagle; $B$, low angle of carpometacarpus; C, low angle of phalanges; D, rotated phalanges.

\section{Pes}

One extra reversed hallux is evident on both feet of the abnormal eagle (Fig. 5). Each is fully functional and fused medially to the base of the proximal phalanx of the original hallux. While functional, they cannot move independently but rather move as a complex with the original toe. The extra hallux on the left foot lacked a talon.

We dissected out the dorsal and plantar tendons of the pes of the abnormal bald eagle for differences in tendinous arrangements and insertions. We list the foot muscles' origins and insertions contributing to the foot below. Figures 6 and 7 illustrate a reflected view of the tendons of the dorsal and plantar sides of the left foot.

M. extensor hallucis longus: This muscle originates on the proximal anteromedial surface of the tarsometatarsus, and inserts on the dorsal surface of the first digit. It extends the hallux. Hudson (1937) stated that in the columbids Columba livia and Zenaida, there are two insertion points. In Accipitridae, Hudson (1937) described a second medial head forming a fleshy sheath about the tendon of the $m$. extensor digitorum longus. In the bald eagle, there are a total of three distinct heads contributing to this muscle. Each accessory head contributes to the main body via a small tendon. The accessory heads lie deep to the $m$. extensor digitorum longus and originate around the tendinous insertion of the $m$. tibialis cranialis on the proximal portion of the anterior surface of the tarsometatarsus. The lateral-most head originates superficial to the origin of $m$. extensor brevis digiti $I V$. The middle head originates immediately adjacent medial to this lateral head. There are two accessory tendons, one of which inserts on the medial side of the base of the phalanx of digit I, whereas the other tendon inserts

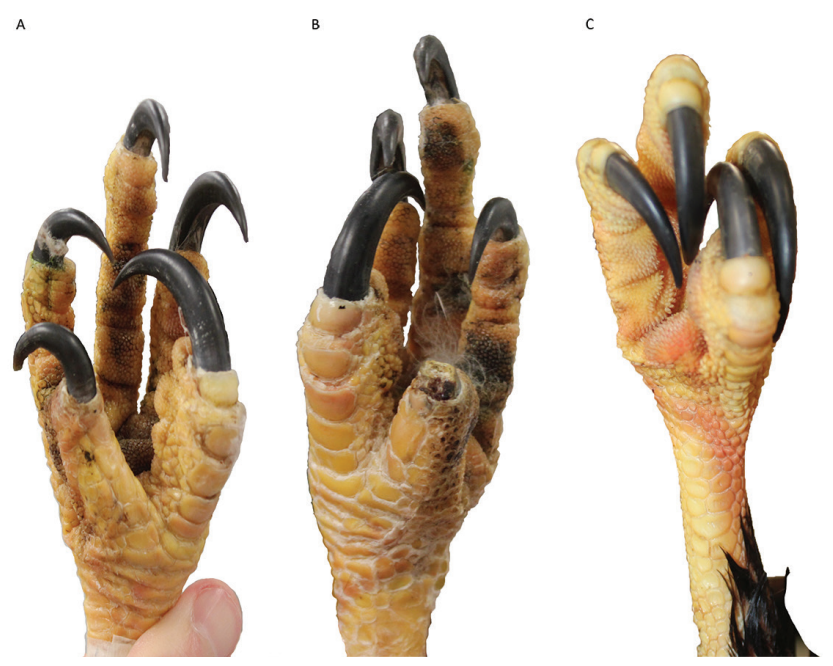

Figure 5. Polydactyly of the feet. A, right foot (abnormal); $B$, left foot (abnormal). C, right foot (normal). 


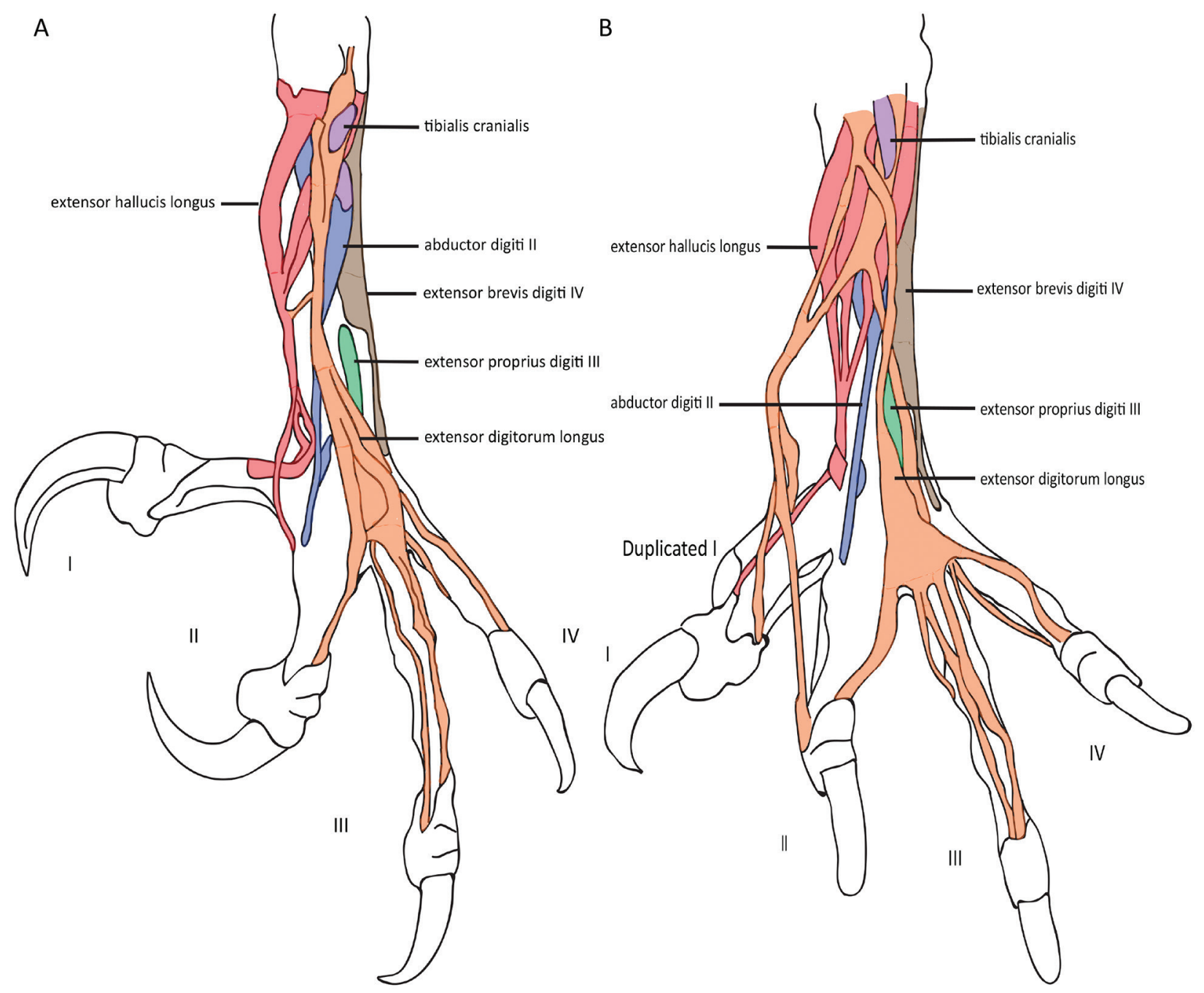

Figure 6. Line drawing of the tendons of the dorsal side of the left feet. A, normal; B, abnormal.

onto the medial side of the proximal phalanx of digit II. A fourth short tendon joins this muscle to the m. extensor digitorum longus where the three heads meet. In the aberrant specimen, three heads exist, but the muscles do not have three insertions. Instead, the three heads converge upon a single inserting tendon. On the left foot of the abnormal bird only the main tendon exists, whereas the accessory tendons are absent.

\section{M. extensor digitorum longus: The origin of this} muscle is on the proximal anterior portion of the tibiotarsus. Proximally on the tarsometatarus, this muscle surrounds the tendon of the $m$. tibialis cranialis which passes through the muscle. It trifurcates to insert on the dorsal surface of pedal digitis II-IV, acting to extend digits II-IV. The branch that goes to the second digit has a large branch going to the distal base of the distal phalanx and a second thinner branch that goes to the lateral proximal end of the second phalanx. The branch that goes to the third digit bifurcates around the base of the proximal phalanx. Both branches further bifurcate themselves. All branches insert on the distal end of the last phalanx (two dorsally, one medially, and one laterally). The branch that goes to the fourth digit bifurcates as well, giving off a branch that inserts on the medial side of the base of the third whereas the other branch inserts at the distal, dorsal base of the fourth phalanx.

On the left foot (but not the right foot) of the aberrant specimen, $m$. extensor digitorum longus has an accessory portion that connects to the main tendon on the proximal tarsometatarsus. This accessory branch has four inserting tendons with one insertion point in the middle between the two fused halluces, one on the distal end of the lateral side of the phalanx of the hallux, one on the distal end of the medial side of the distal phalanx of digit II, and one inserting on the base of the proximal phalanx of digit III. These extra tendons would contribute to extending the first digit and thus all toes can be extended by this muscle in the left foot.

M. abductor digiti II: This muscle originates from the medial side of the distal half of the tarsometatarsus and inserts on the base of the proximal phalanx of digit II. 

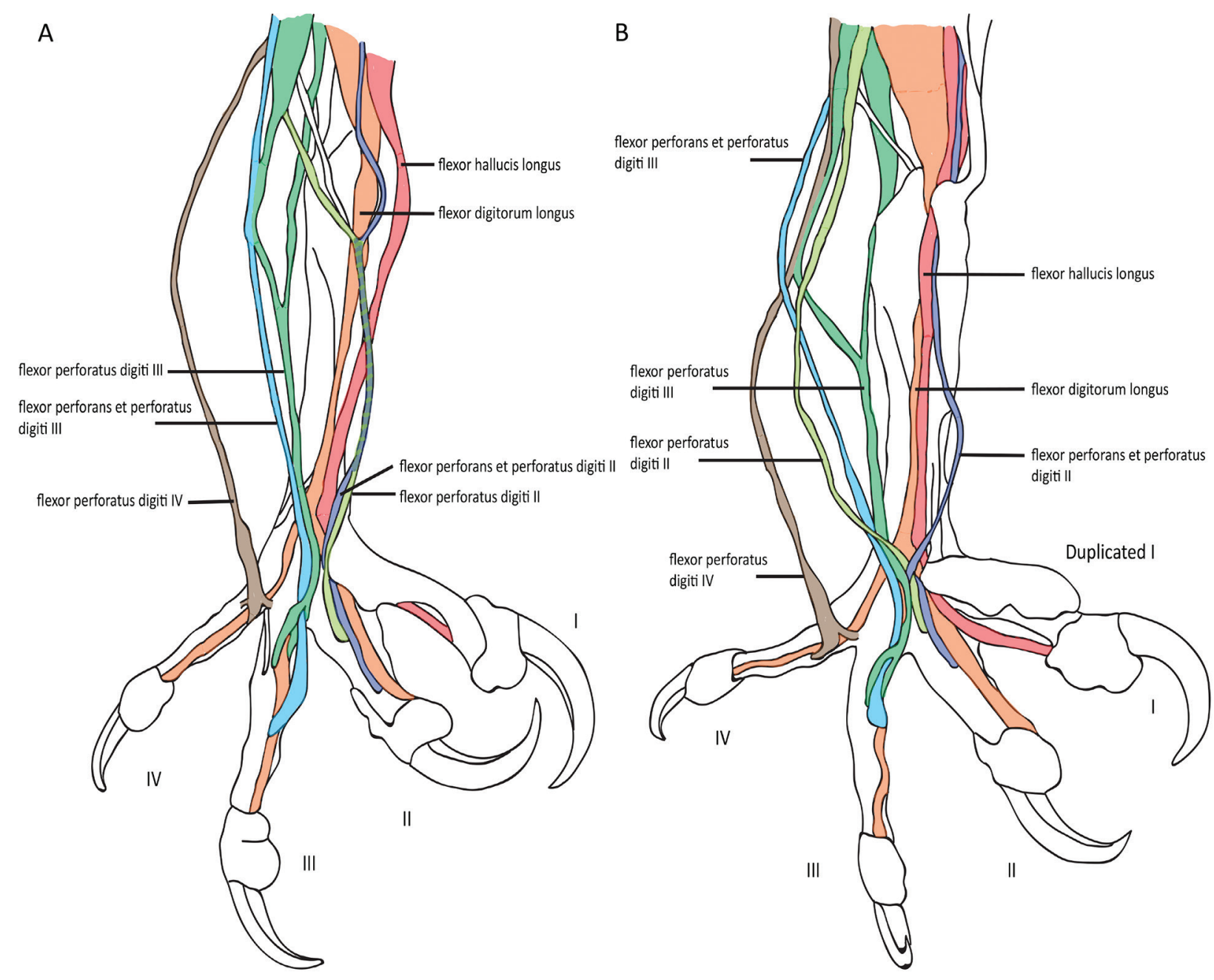

Figure 7. Line drawing of the tendons of the plantar side of the left feet. A, normal; B, abnormal.

There exists a small muscular portion covered by a long tendon near the base of digit II, but this tendon passes proximally to join to a much larger muscular portion deep to the $m$. extensor hallucis longus that borders the insertion of the $m$. tibialis cranialis. Hudson (1937) described this as being almost the entire length of the tarsometatarsus in Accipitridae. In the aberrant bird, the tendon is shifted slightly more central to the shaft of the tarsometatarsus.

M. extensor proprius digiti III: This muscle originates from the anterior surface of the distal third of the tarsometatarsus, and inserts by a tendon on the dorsal surface of the base of the proximal phalanx of digit III. It helps extend digit III. It is obscured, deep to the m. extensor digitorum longus. Hudson (1937) described this as being confined to the distal half or third of the tarsometatarsus in accipiters in general. In both the normal and abnormal specimens, this muscle was confined to about the distal third of the tarsometatarsus, consistent with Hudson's (1937) observations. No abnormalities were observed in the deformed specimen.
M. abductor digiti IV: This muscle originates from the hypotarsus and the posterolateral ridge of the tarsometatarsus. Its tendon inserts on the lateral side of the proximal phalanx of digit IV in the bald eagle. It inserts on the lateral side of the second phalanx in Pandion and Falco (Hudson 1948). This muscle lies deep to the $m$. flexor digitorum longus on the plantar side of the foot. There were no irregularities of this muscle within the aberrant specimen.

M. extensor brevis digiti IV: Originates on the anterolateral surface of the tarsometatarsus proximally, and inserts onto the medial side of the base of the proximal phalanx of digit IV. No anomalies were observed with this muscle on either foot of the abnormal bird.

M. flexor hallucis brevis: Originates on the hypotarsus and the posterior shaft of the tarsometatarsus as two bellies (for clarity here, bellies 1 and 2), one deep to the other (belly 2 is deep to belly 1). Both bellies have their own tendon, each of which inserts onto the ventral portion of the proximal end of the phalanx of digit I. This muscle lies to the side of and somewhat deep to the $m$. flexor hallucis 
longus on the plantar side of the foot. In the abnormal specimen, the deeper belly (belly 2) has a tendon that splits in two as opposed to that of the normal specimen in which this tendon does not split. These two tendons insert ventrally onto the most proximal portion of the phalanx (Fig. 8 ). The superficial belly of the abnormal specimen inserts on the ventral surface of the fused area and is immediately lateral to the midline of the base of the extra toe. These tendons assist in flexion of the hallux, and in the abnormal eagle, flexion of the fused halluces.

M. flexor hallucis longus: This muscle has two heads, one on the lateral and one on the caudal aspects of the distal femur near the condyles (Lamas et al. 2014). This muscle inserts onto the ventral surface of the distal end of the phalanx of the hallux. The tendon is connected to the tendon of the $m$. flexor digitorum longus for the distal third of their length by a vinculum. The muscle acts in ankle extension and knee flexion (Lamas et al. 2014). No abnormalities exist with this muscle in the aberrant eagle.

M. flexor digitorum longus: This muscle has two heads, one on the proximal tibiotarsus and the other on the distal third of the fibula (Lamas et al. 2014). It trifurcates above the metatarsophalangeal joint to insert onto the distal, ventral phalanx of toes 2-4. It flexes digits II, III, and IV and assists in ankle extension (Lamas et al. 2014). No deformities were observed of this muscle in the abnormal specimen.

\section{M. flexor perforans et perforatus digiti II: The origin} of this muscle is on the external femoral condyle and on part of the deep fibular tendon of the $m$. gastrocnemius lateralis, and has a tendinous insertion on the lateral side of the middle phalanx of digit II. This muscle functions to flex digit II and extend the ankle (Lamas et al. 2014). An interesting

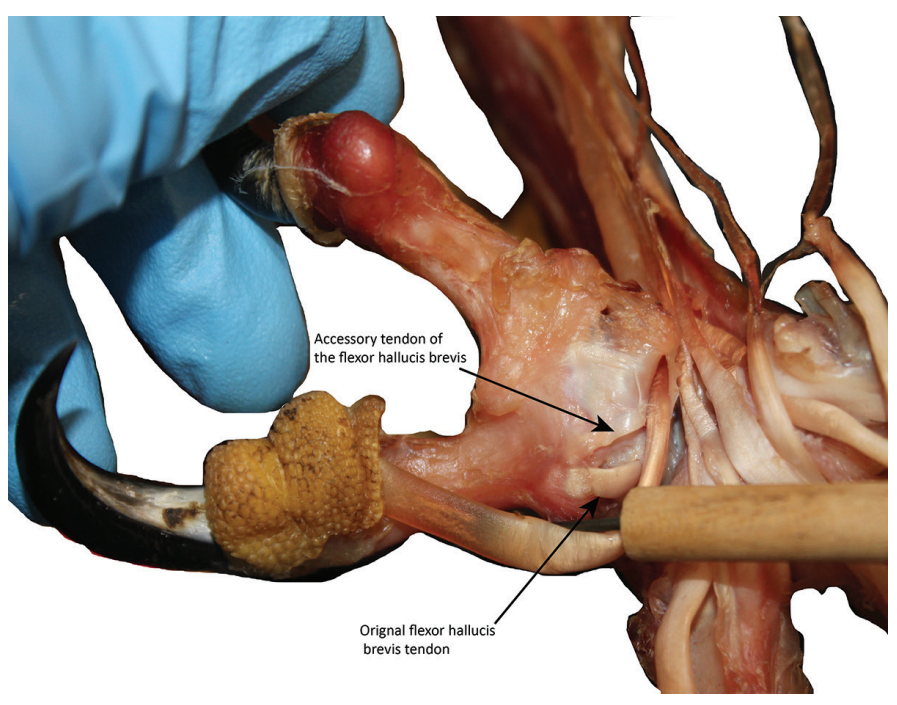

Figure 8. Extra tendinous insertion of $m$. flexor hallucis brevis. difference of the tendon of this muscle in the aberrational eagle is described below in $m$. flexor perforatus digiti II.

M. flexor perforans et perforatus digiti III: The origin of this muscle is on the lateral tibiofemoral ligaments and on the $m$. flexor perforatus digiti $I V$. This muscle has a tendinous insertion on the middle phalanx of digit III, and functions to flex digit III and extend the ankle (Lamas et al. 2014). The tendon of this muscle in the deformed specimen is described further below in vinculum tendinum flexorum.

M. flexor perforatus digiti II: This muscle forms a common origin with the $m$. flexor perforatus digiti III, and inserts ventrally onto the lateral side of the proximal phalanx. It flexes the second digit. In the normal eagle, the tendinous portion of this muscle fuses with the tendon of the $m$. flexor perforans et perforatus digiti II at the midshaft of the tarsometatarsus. In the abnormal bird, the tendinous portion of this muscle does not fuse on the left foot, but does on the right, creating an asymmetric difference. This lack of fusion between the tendons of $m$. flexor perforatus digiti II and $m$. flexor perforans et perforatus digiti II in the left foot of the abnormal bird allows for total independence of the two muscles action. In the accipiter, Pandion, $m$. flexor perforans et perforatus digiti II fuses with $m$. flexor perforatus digiti II at the level of the tibial cartilage (George and Berger 1966).

M. flexor perforatus digiti III: The origin of this muscle is by two tendons, one on the cranial portion of the fibula and one on the medial side of the medial condyle of the femur. The tendon fuses with the tendon of $m$. fibularis longus. It splits into two branches at the proximal phalanx to insert onto the proximal phalanx and flexes digit III. It attaches to $m$. flexor perforans et perforatus digiti III via a vinculum at a level near the proximal end of the tarsometatarsus. In the aberrant specimen the tendon attaches to the tendon of the $m$. flexor perforatus digiti $I V$ on the left foot but not the right foot which remains normal in configuration. Strangely, this also occurs on the right foot of the normal bird suggesting this condition may possibly be normal intraspecific variation. Lamas et al. (2014) mentioned that in some species the tendon of $m$. flexor perforatus digiti III fuses to the tendon of $m$. flexor perforans et perforatus digiti II. The vinculum is described below. The $m$. flexor perforatus digiti $I V$ joining to $m$. flexor perforatus digiti III weakly assists in flexing the fourth digit along with the third.

\section{M. flexor perforatus digiti IV: The $m$. flexor perforatus} digiti $I V$ originates on the superficial side of the origin of $m$. flexor perforatus digiti III. It splits into at least three branches at the proximal phalanx inserting onto either side of the proximal and middle phalanges of digit IV and flexes digit IV in both the normal and abnormal specimens. No irregu- 
larities were observed in either specimen besides an irregular vinculum connection in the left foot of the abnormal bird which is described below in vinculum tendinum flexorum.

\section{Vinculum tendinum flexorum}

This is a tendinous, fibroelastic band connecting the tendons of $m$. flexor perforans et perforatus digiti III and $m$. flexor perforatus digiti III at a level near the proximal end of the tarsometatarsus in the bald eagle. This condition is unlike that of the turkey, chicken, and goose in which the vinculum occurs at the distal-most end of the tarsometatarsus (as per figs. 183-185 of Ghetie 1976). In the aberrant specimen, however, the vinculum connects the tendon of $m$. flexor perforatus digiti III with the tendon of $m$. flexor perforatus digiti IV in the left foot. Oddly, in the right foot of the normal specimen this same condition exists which could indicate this is a simple case of intraspecific variation but more samples are needed to confirm this. Hudson (1937) listed the vinculum's occurrence in many bird taxa including: Gavia, Sula, Anatidae, Cathartidae, Sagittarius, Galliformes, Grus, Fulica, Totanus, Larus, Pterocles, Columba, Zenaida, Goura, Gallicolumba, and Tauraco. They also mentioned that the vinculum has not been found in the accipiter, Buteo. To our knowledge, a vinculum uniting $m$. flexor perforatus digiti III with $m$. flexor perforatus digiti $I V$ has never been described in any bird, although we do not discount that possibility.

A second vinculum is present connecting $m$. flexor digitorum longus and $m$. flexor hallucis longus. The arrangement of the deep plantar tendons in both bald eagle specimens closely resembles type 3 of Gadow and Selenka (1891) wherein the $m$. flexor hallucis longus is connected to the $m$. flexor digitorum longus for the bottom one-third of the tarsometatarsus near the trifurcation of the $m$. flexor digitorum longus and along the portion of the $m$. flexor digitorum longus that contributes to digits II and III. In uniting these tendons, this vinculum eliminates the independence of their actions.

\section{Ligamentum obliquum hallucis and ligamen- tum transversum metatarsale}

In the aberrant specimen, both insert onto the middle point of the fused halluces on a region that is comparable to that of the condition observed in the normal specimen. The lig. obliquum hallucis extends from the base of the proximal phalanx of the hallux distally to the medial side of the base of the proximal phalanx of digit II acting to limit hyperextension of the hallux (Baumel et al. 1993) normally. In the aberrant bird, as mentioned, the lig. obliquum hallucis attaches to the middle point of the fused halluces (a similar region of attachment to the normal placement) and similarly acts to limit hyperextension of the fused halluces (Fig. 9). The lig. transversum metatarsale unites tuberositas

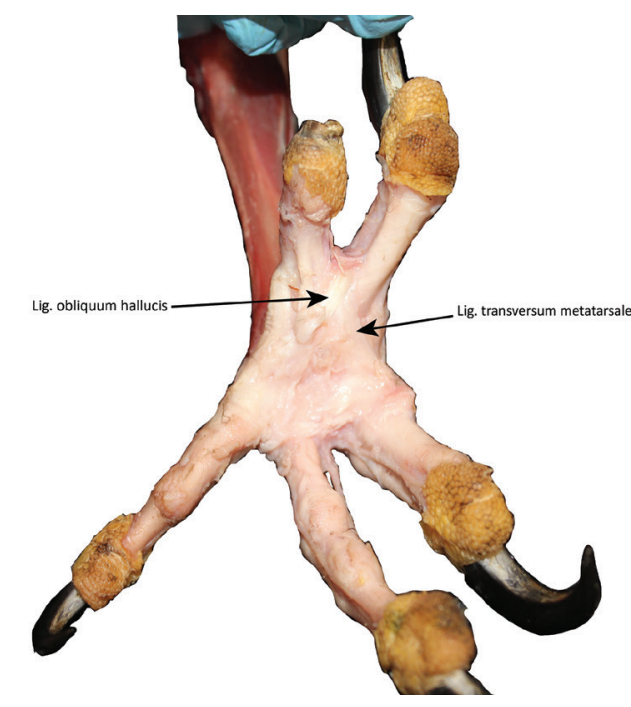

Figure 9. Plantar view of the ligamentum obliquum hallucis and ligamentum transversum metatarsale of the aberrant eagle.

lateralis of the distal end of metatarsale I and the adjoining proximal phalanx of the hallux with the lateral epicondyle of os metatarsale IV (Baumel et al. 1993). Despite the presence of a fused region due to the extra hallux, the attachment sites of these ligaments remained, more or less, similar.

\section{POSSIBLE EXPLANATIONS FOR THE MALFORMATIONS}

Arsenic is known to cause a myriad of problems in birds and other animals like apoptosis, tissue damage, and tumor formation (Khan et al. 2014), learning issues (Nagaraja and Desiraju 1994), behavioral issues (Whitworth et al. 1991), and decreased adult weight gain, delayed egg laying, and decreased egg weight (Stanley et al. 1994). Arsenic accumulates in most organs (particularly the liver) where its biomethylation disables enzymes involved in cellular metabolism and repair or synthesis of DNA and may lead to cell death (Khan et al. 2014). Despite the problems that animals may face with increased arsenic levels and although the abnormal specimen lived in an area that had been cleaned of high arsenic levels, no elevated levels of arsenic or any other elements were found in the specimen. Thus, arsenic contamination does not appear to be the cause of the observed anatomical abnormalities. The asymmetrical aberrations may be the result of mutations in the Pitx 1 and Tbx5 genes. Prior experimental manipulations of Pitx 1 in chicken embryos (e.g., Logan and Tabin 1999) resulted in repatterning of the skeleton, muscles, and tendons of the hindlimb as does experimentally induced ectopic expression of $T b x 5$ (e.g., Takeuchi et al. 1999). Domyan et al. (2016) demonstrated that mutations of these genes in pigeons caused musculo- 
skeletal issues of the hindlimb such as a shortened fibula, rearrangement of the $m$. fibularis longus, and fibers of the $m$. flexor perforans et perforatus digiti III fusing with those of the $m$. fibularis longus. The dysgenesis of the feathers, especially the feather bifurcations, remains unknown as genetic and developmental work is needed to explore such aberrations. Koski (2002) listed a number of non-genetic and non-developmental reasons for common feather issue causes including illness, stress, malnutrition, mineral deficiencies, toxins, parasites, and disease and infection. It is perhaps possible that the added physical stresses of the musculoskeletal aberrations induced or contributed to the feather aberrations (such as the feather stress bars).

\section{SUMMARY}

Two juvenile bald eagles (one normal and one abnormal specimen) were dissected to describe anatomical differences between the aberrant and normal individuals. An extended feather sheath, stress bars, bifurcated feathers, severe curvature of some primaries, and ingrown feathers were all observed in the abnormal specimen. In the right forearm of the abnormal specimen, an anomalous tendon stemming from the $m$. extensor carpi radialis was found to have inserted into the skin a short distance from its origin. Additionally, there is a noticeable limitation in the degree of extension seen in the hands between the two individuals with the abnormal bird displaying a reduced extension of only about $140^{\circ}$ (whereas normal extension is at about $180^{\circ}$ ). This lack of mobility may be due to a dysfunctional radiale that makes premature contact with the radius during extension. The phalanges suffer from severe distortion as well. A combination of feather issues and hand and phalangeal issues preclude and impair the aberrant eagle's ability to fly. Polydactyly is a readily observable feature in the aberrant specimen with an additional hallux on both feet. The aberrant halluces are fused to the original hallux. On the left aberrant foot, the $m$. extensor digitorum longus has an accessory portion that inserts between the fused halluces, on the lateral side of the original hallux, and on the medial side of the second digit. These additional insertions might help extend the fused halluces. Additional assistance in moving the fused halluces may come from an additional inserting tendon of $m$. flexor hallucis brevis. Lastly, an abnormal joining of $m$. flexor perforatus digiti III to that of $m$. flexor perforatus digiti $I V$ was observed not only on the left abnormal foot but also the right normal foot.

A pre-existing genetic disposition, environmental stress, poor nutrition, or a combination of these factors could have caused these atypical characteristics. Although the aberrant specimen was found in an area previously exposed to high levels of arsenic, prior toxicology screening using atomic absorption spectrometry tests could not show elevated levels of toxins within the liver or kidneys, indicating the mutations were likely genetic or developmental in origin. Environmental stress could certainly have still contributed to its poor overall health.

\section{ACKNOWLEDGEMENTS}

First and foremost, we thank Kevin and Karin Buynie for watching the particular nest of the abnormal specimen before any eggs were even laid. Had it not been for their continued observations of the nest, this remarkable specimen would have perished undiscovered in the wild. We also thank Dr. Erica Miller, Dr. Scott Echols, and Dr. Susan Orosz for the specimens. We are also grateful to reviewers who helped to improve this manuscript.

Conflict of interest: None declared.

\section{LITERATURE CITED}

Baumel, J.J., S.A. King, J.E. Breazile, H.E. Evans, and J.C. Vanden Berge. 1993. Handbook of Avian Anatomy: Nomina Anatomica Avium, 2nd edn. Prepared by the International Committee on Avian Anatomical Nomenclature, a committee of the World Association of Veterinary Anatomists, Published by the Nuttall Ornithological Club, Cambridge, Massachusetts, 779 pp.

Bebe, C.W. 1910. Three cases of supernumerary digit in the broad-winged hawk (Buteo brachypterus). Zoologica 1:150-152.

Coale, H.K. 1887. Ornithological curiosities_a hawk with nine digits, and a bobolink with spurs on its wings. Auk 4:231-233.

Cole, R.K. 1942. The "talpid lethal" in the domestic fowl.

Journal of Heredity 33:83-86.

Cooper, J.E. 1984. Developmental abnormalities in two British falcons (Falco spp.). Avian Pathology 13:639-645.

Domyan, E.T., Z. Kronenberg, C.R. Infante, A.I. Vickrey, S.A. Stringham, R. Bruders, M.W. Guernsey, S. Park, J. Payne, R.B. Beckstead, G. Kardon, D.B. Menke, M. Yandell, and M.D. Shapiro. 2016. Molecular shifts in limb identity underlie development of feathered feet in two domestic avian species. Elife 5:e12115

Ester, H. 1937. Ein seltener Fall von Hyperdactylie beim Turmfalken, Falco t. tinnunculus. Mitt Versammlung Österreich Ornitologia 5:111-115.

Fox, N.C. 1989. A unilateral extra digit in a wild common buzzard (Buteo buteo). Avian Pathology 18:193-196.

Gadow, H. and E. Selenka. 1891. Aves, Teil 1: Anatomischer. Pp. 1-1008 in H.G. Bronn's "Klassen und Ordnungen des Their-Reichs, in Wort und Bild.” Leipzig: C.E. Winter'sche Verlagshandlung.

George, J.C. and A.J. Berger. 1966. Avian Myology. New York: Academic Press, 500 pp.

Ghetie, V. 1976. Anatomical Atlas of Domestic Birds. Academiei Republicii Socialiste, Bucharest, Romania, 294 pp. 
Heidenreich, M. 1997. Birds of Prey, Medicine and Management-Congenital Abnormalities. Blackwell Science, Oxford, England, 304 pp.

Herrara, J.M. and I. Berkunsky. 2017. Polidactilia y asimetría fluctuante en el "loro hablador" (Amazona aestiva): ‘signos de estrés del desarrollo? Revista Veterinaria 28:62-64.

Hollander, W.F. and W.M. Levi. 1942. Polydactyly, a sub-lethal character in the pigeon. Journal of Heredity 33:385-391.

Hudson, G.E. 1937. Studies on the muscles of the pelvic appendage in birds. American Midland Naturalist 18:1-108.

Hudson, G.E. 1948. Studies on the muscles of the pelvic appendage in birds II: the heterogeneous order Falconiformes. American Midland Naturalist 39:102-127.

Khan, A., H.I. Hussain, A. Sattar, M.Z. Khan, and R.Z. Abbas. 2014. Toxico-pathological aspects of arsenic in birds and mammals: A review. International Journal of Agriculture and Biology 16:1213-1224.

Koski, M.A. 2002. Dermatologic diseases in psittacine birds: an investigational approach. Seminars in Avian and Exotic Pet Medicine 11:105-124.

Kummerloeve, H. 1952. Ein weiterer Fall von Hyperdactylie beim Tagraubvogel. Beiträge zur Vogelkunde 2:102-108.

Lamas L.P., R.P. Main, and J.R. Hutchinson. 2014. Ontogenetic scaling patterns and functional anatomy of the pelvic limb musculature in emus (Dromaius novaehollandiae). PeerJ 2:e716; DOI $10.7717 /$ peerj.716

Landauer, W.A. 1946. A second diploid mutation of the fowl. Journal of Heredity 37:57-62.

Logan M. and C.J. Tabin. 1999. Role of Pitx1 upstream of Tbx4 in specification of hindlimb identity. Science 283:1736-1739.

Lönnberg E. 1907. Egendomlig dubbelmissbildning hos sparfhök. Fauna Flora 2:212-213.
Nagaraja T.N. and T. Desiraju. 1994. Effects on operant learning and brain acetylcholine esterase activity in rats following chronic inorganic arsenic intake. Human and Experimental Toxicology 13:353-356.

Pourlis, A.F. 2011. Developmental malformations in avian species. Manifestations of unknown or genetic etiology - a review. Asian Journal of Animal and Veterinary Advances 6:401-415.

Reichenau, W.V. 1880. Ein fünfzehiger Raubvogel. Kosmos 7:318-319.

Samour, J. 2000. Five-toed falcon. Exotic DVM 2:5.

Stanley Jr., T.R., J.W. Spann, G.J. Smith, and R. Rosscoe. 1994. Main and interactive effects of arsenic and selenium on mallard reproduction and duckling growth and survival. Archives of Environmental Contamination and Toxicology 26:444-451.

Takeuchi, J.K., K. Koshiba-Takeuchi, K. Matsumoto, A. VogelHöpker, M. Naitoh-Matsuo, K. Oguro, N. Takahashi, K. Yasuda, and T. Oguro. 1999. Tbx5 and Tbx4 genes determine the wing/leg identity of limb buds. Nature 398:810-814.

Taylor L.W. and C.A. Gunns. 1947. Diplopodia: a lethal form of polydactyly in chickens. Journal of Heredity 38:66-71.

Trinkaus, K., F. Müller, E.F. Kaleta. 1999. Polydactylie bei einem Turmfalken (Falco tinnunculus tinnunculus, Linné, 1758)—ein Fallbericht. Zeitschrift für Jagdwissenschaft NLM 45:66-72.

Vedder, O. 2000. Torenvalk Falco tinnunculus met vleuglafwijking. Takkeling 8:140-141.

Whitworth, M.R., G.W. Pendleton, D.J. Hoffman, and M.B. Camardese. 1991. Effects of dietary boron and arsenic on the behavior of mallard ducklings. Environmental Toxicology and Chemistry 10:911-916. 